\title{
When COVID-19 exacerbates inequities: The path forward for generating wellbeing
}

\author{
Meg A. Warren · Samit D. Bordoloi
}

\section{Introduction}

The novel coronavirus (COVID-19) that was detected in late 2019 has spread across the globe and was labelled a pandemic by the World Health Organization on March 11, 2020 (WHO, 2020). The virus can cause respiratory infection of varying intensities that can lead to severe illness and death. Its rapid spread has led to stay-at-home orders, lockdowns, and shutdowns across the world (Lancet, 2020; Lau et al., 2020; Lavezzo et al, 2020; Thornton, 2020). This has caused widespread fear and changed everyday life for the masses, in an unprecedented manner. Despite its usefulness in curtailing the spread of the virus, shuttering of businesses, schools, public events, and activities have a tremendous impact on psychological health (Holmes et al., 2020; Pfefferbaum, B \& North, 2020) and socio-economic health (Nicola et al., 2020).

The purpose of this timely special issue is two-fold. Our first goal is to narrow focus on the impact of the COVID-19 pandemic on psychological wellbeing. Going beyond discussions of the physical implications of the disease itself, we consider the psychological implications of the social and institutional measures used to control the pandemic. Importantly, departing from extant discussions of how the COVID-19 pandemic is leading to psychological distress and dysfunction, which carries the implicit goal of being free of distress and dysfunction, this special issue is interested in moving forward to how we can actively generate psychological and social wellbeing during and post COVID-19.

Past research on wellbeing has leaned heavily toward individual actions and behaviors to generate wellbeing, given the underlying assumption that individuals have the autonomy to choose activities, engage in experiences, and take measures to enhance their own wellbeing (Hendriks et al., 2019; Lyubomirsky, 2008). In the context of COVID-19, however, top-down institutional actions such as mandating social distancing, requiring online learning in schools, colleges and universities, mandating remote work for some occupations, in others, requiring essential workers to risk their health to retain their jobs, restricts individual autonomy to engage in some actions that enhance wellbeing. Further, restrictions on autonomy itself may hurt wellbeing (Deci \& Ryan, 2008; Yu, Levesque-Bristol, \& Maeda, 2018). Therefore, current conditions make it important that institutions focus not only on the control of disease, but also prioritize wellbeing. This special issue carries implications for how institutions can generate wellbeing in the face of COVID-19 and in a post-COVID-19 world.

Our second goal for the special issue is to focus on inequities. Numerous studies across a variety of contexts, age groups, and cultures show that inequity/inequality is linked to lower wellbeing (Azzopardi et al., 2019; Gjerdingen, McGovern, Bekker, Lundberg, \& Willemsen, 2000; Savage, McConnell, Emerson, \& Llewellyn, 2014; Schneider, 2016; Slopen, Lewis, \& Williams, 2016). Across the world, the COVID-19 disease itself has had a disproportionate impact on 
minority and low-income populations (Khalatbari-Soltani, S, Cumming, Delpierre, \& KellyIrving, 2020). For example, within the United States hospitalization and mortality rates have been disproportionately high for Black and Latino populations (van Dorn et. al, 2020). Perhaps, more importantly the use of social distancing as the key intervention in its various forms such as quarantine, lockdown and physical distancing has had a devastating impact on those populations who were already subject to social and economic marginalization. Individuals from low-income backgrounds who are more likely to work in informal employment (e.g. domestic work, farm labor), and belong to racial and ethnic minority groups, do not have the financial buffer to endure extended social distancing protocols such as lockdowns (Hutchins et.al 2009). Migrant workers across the world are especially vulnerable due to their marginal socioeconomic status, living in crowded or substandard environments and being restricted in their ability to access health and welfare services (Ratha et.al, 2020). The lockdown measures have a large impact on service oriented industries, which tend to have high female employment (Osland, Røysamb, \& Nortvedt, 2020), disproportionately affecting women. Further, due to gender role stereotypes, women undertake disproportionate amounts of unpaid caregiving responsibilities, the burdens of which are exacerbated due to lack of support systems (e.g., extended family) during the pandemic (Collins, Landivar, Rupoanner, \& Scarborough, 2020). An unintended consequence of quarantine is an escalation in domestic violence worldwide (Mazza, Marano, Lai, Janiri, \& Sani, 2020; Usher, Bhullar, Durkin, Gyamfi, \& Jackson, 2020). This special issue considers the impact of the pandemic on the wellbeing of marginalized groups and with particular attention to how wellbeing can be intentionally generated for those most affected.

\section{Contexts that impact wellbeing}

Work and employment is a key arena in which existing inequities have been exacerbated by the pandemic leading to disproportionate impacts on wellbeing. In certain professions, employees such as managers and teachers have been able to work from home through use of remote-work technology. However, marginalized groups (e.g., low income) are disproportionately burdened by unfavorable conditions at home (e.g., cramped living spaces, poor internet access) that impact wellbeing while attempting to work from home. In other jobs (e.g., entertainment, retail) that cannot be performed from home, shuttering of businesses has led to employees being forced to stay out of work and lose income. Finally, several groups of workers such as custodial staff, factory workers, farm workers, grocery store employees and gig workers (e.g, rideshare drivers, delivery couriers) have been deemed "essential" (Baker, Peckham \& Seixas, 2020; Pisano, Zanini, \& Sadun, 2020; Leung, 2020) and therefore, required to be physically present at work. Such institutional action forces individuals to put their physical health and psychological wellbeing (e.g., fear of contracting COVID-19) at risk to ensure economic security and provide necessary services to others (The Lancet, 2020). Health care professionals find themselves as frontline workers against COVID-19, risking not only higher rates of infection but also significant psychological stressors (Ehlrich, McKenney \& Elkbuli, 2020; Que, Shi, Deng et.al, 2020). As institutions have become agents that deepen the vulnerability of workers, they must also go beyond traditional measures to actively promote wellbeing.

The pandemic has also resulted in significant disruptions to the education sector. Given the large youth population and high degree of social contact, educational institutions are particularly susceptible to rapid spread of infection (Van, D et.al 2010). Academic institutions have to utilize wellbeing interventions that balance the competing goals of minimizing infection rates while actively promoting educational and socio-emotional growth, particularly among vulnerable students such as first generation students, low-income students, students with disability and 
female students who are likely to experience the disproportionate impact of COVID-19 (McCarthy, 2020; Van Lancker \& Parolin, 2020; Zhang et al., 2020; Zhou et al., 2020).

\section{Contributions of this Special Issue}

The papers in this special issue use systematic reviews and empirical research to discuss how wellbeing can be generated in the face of COVID-19, particularly among vulnerable populations. Wang and colleagues provide a systematic overview of international research on how pandemics impact low-wage migrant laborers, who are especially vulnerable due to their marginal sociolegal status in host countries. Their findings foreground the importance of long-term interventions that bring the rights of migrants into public consciousness and address their physical, social and psychological wellbeing both during and after the pandemic. Matteo and colleagues, in their study on Italian healthcare professionals, demonstrate that increased trust and greater gratitude from the overall population and a feeling of accomplishment and meaning among healthcare professionals can boost their job satisfaction during a pandemic and reduce prior disparities in wellbeing. Bono and colleagues examine the role of grit and gratitude in enhancing wellbeing among students from diverse backgrounds in the United States. Their research offers potential for universities and colleges to create wellbeing interventions that can be adapted for online delivery and reach student populations who are at the highest risk of academic failure. In their paper on promoting workers' wellbeing, Pacheco and colleagues note that current research is lacking discussion of resilience levers that workplace interventions should target during a pandemic. Their study emphasizes the importance of fostering job security in combination with resilience promoting interventions, suggesting that individual level wellbeing interventions work best when institutional structures for wellbeing are in place. Finally, Fortier's paper considers structural injustices that have disproportionately impacted women during the pandemic and outlines the obligations of the state in creating and prioritizing policies that promote the wellbeing of women, particularly single mothers.

\section{Path forward}

This special issue brings together insights from around the world on how wellbeing can be generated, particularly for the most vulnerable populations, in the face of a pandemic. Past wellbeing research has documented how the focus on non-WEIRD populations (Hendriks et al., 2019) and marginalized groups (Rao \& Donaldson, 2015) have been on the fringes in the field. This special issue serves to center focus on these groups during these tumultuous times. However, there is still much work to be done. Research on generating wellbeing among marginalized groups across the world - from low caste groups in India, indigenous groups in Australia, child soldiers in Congo, refugees in Sweden, ethnic minorities in the U.S., to construction workers in the United Arab Emirates - continues to remain scant. As we move forward, we urge researchers to sharpen focus on how wellbeing can be generated among vulnerable communities, not only during times of global crisis but also when we "return to a new normal."

\section{Authors \\ Meg A. Warren \\ Western Washington University \\ meg.warren@wwu.edu}

Samit D. Bordoloi 
Western Washington University

samit.bordoloi@wwu.edu

\section{Publishing Timeline}

Published 13 August 2020

\section{References}

Azzopardi, P. S., Hearps, S. J. C., Francis, K. L., Kennedy, E. C., Mokdad, A. H., Kassebaum, N. J., Lim, S., Irvine, C. M. S., Vos, T., Brown, A. D., Dogra, S., Kinner, S. A., Kaoma, N. S., Naguib, M., Reavley, N. J., Requejo, J., Santelli, J. S., Sawyer, S. M., Skirbekk, V., .. Patton, G. C. (2019). Progress in adolescent health and wellbeing: Tracking 12 headline indicators for 195 countries and territories, 1990-2016. The Lancet, 393(10176), 1101-1118. https://doi-org.ccl.idm.oclc.org/10.1016/S01406736(18)32427-9

Baker, M. G., Peckham, T. K., \& Seixas, N. S. (2020). Estimating the burden of United States workers exposed to infection or disease: a key factor in containing risk of COVID-19 infection. PLoS One, 15(4), e0232452.

Collins, C., Landivar, L. C., Ruppanner, L., \& Scarborough, W. J. (2020). COVID-19 and the Gender Gap in Work Hours. Gender, Work \& Organization.

Deci, E. L., \& Ryan, R. M. (2008). Self-determination theory: A macrotheory of human motivation, development, and health. Canadian Psychology/Psychologie Canadienne, 49(3), 182-185. https://doiorg.ccl.idm.oclc.org/10.1037/a0012801

Ehrlich, H., McKenney, M., \& Elkbuli, A. (2020). Protecting our healthcare workers during the COVID-19 pandemic. The American Journal of Emergency Medicine, 38(7), 1527-1528. https://doi.org/10.1016/j.ajem.2020.04.024

Gjerdingen, D., McGovern, P., Bekker, M., Lundberg, U., \& Willemsen, T. (2000). Women's work roles and their impact on health, well-being and career: Comparisons between the United States, Sweden and The Netherlands. Women $\mathcal{E}$ Health, 31(4), 1-20. https://doiorg.ccl.idm.oclc.org/10.1300/J013v31n04_01

Hendriks, T., Warren, M. A., Schotanus-Dijkstra, M., Hassankhan, A., Graafsma, T., Bohlmeijer, E., \& de Jong, J. (2019). How WEIRD are positive psychology interventions? A bibliometric analysis of randomized controlled trials on the science of well-being. The Journal of Positive Psychology, 14(4), 489-501.

Holmes, E. A., O'Connor, R. C., Perry, V. H., Tracey, I., Wessely, S., Arseneault, L., ... \& Ford, T. (2020). Multidisciplinary research priorities for the COVID-19 pandemic: A call for action for mental health science. The Lancet Psychiatry.

Hutchins, S. S., Fiscella, K., Levine, R. S., Ompad, D. C., \& McDonald, M. (2009). Protection of racial/ethnic minority populations during an influenza pandemic. American Journal of Public Health, 99(S2), S261-S270.

Khalatbari-Soltani, S., Cumming, R. G., Delpierre, C., \& Kelly-Irving, M. (2020). Importance of collecting data on socioeconomic determinants from the early stage of the COVID-19 outbreak onwards. Journal of Epidemiology and Community Health, 74, 620-623

Lancet, T. (2020). India under COVID-19 lockdown. Lancet (London, England), 395(10233), 1315.

Lancet, T. (2020). The plight of essential workers during the COVID-19 pandemic. Lancet (London, England), 395(10237), 1587. https://doi.org/10.1016/S0140-6736(20)31200-9

Lau, H., Khosrawipour, V., Kocbach, P., Mikolajczyk, A., Schubert, J., Bania, J., \& Khosrawipour, T. (2020). The positive impact of lockdown in Wuhan on containing the COVID-19 outbreak in China. Journal of Travel Medicine, 27(3), taaa037.

Lavezzo, E., Franchin, E., Ciavarella, C., Cuomo-Dannenburg, G., Barzon, L., Del Vecchio, C., ... \& Abate, D. (2020). Suppression of COVID-19 outbreak in the municipality of Vo, Italy. medRxiv.

Lyubomirsky, S. (2008). The how of happiness: A scientific approach to getting the life you want. Penguin. 
Mazza, M., Marano, G., Lai, C., Janiri, L., \& Sani, G. (2020). Danger in danger: Interpersonal violence during COVID-19 quarantine. Psychiatry Research, 289, 113046. https://doi.org/10.1016/j.psychres.2020.113046

McCarthy, C. (2020). Support first-generation college students through struggles triggered by national crisis. Student Affairs Today, 23(4), 1.

Nicola, M., Alsafi, Z., Sohrabi, C., Kerwan, A., Al-Jabir, A., Iosifidis, C., ... \& Agha, R. (2020). The socioeconomic implications of the coronavirus and COVID-19 pandemic: A review. International Journal of Surgery.

Osland, K. M., Røysamb, M. G., \& Nortvedt, J. (2020). The Impact of Covid-19 on the Women, Peace and Security Agenda. NUPI Covid-19 Brief.

Pfefferbaum, B., \& North, C. S. (2020). Mental health and the Covid-19 pandemic. New England Journal of Medicine.

Pisano, G. P., Zanini, M., \& Sadun, R. (2020). Lessons from Italy's Response to Coronavirus. Harvard Business School Cases, 1. Retrieved from https://hbr.org/2020/03/lessons-from-italys-response-tocoronavirus

Que J, Shi L, Deng J, et al. Psychological impact of the COVID-19 pandemic on healthcare workers: a cross-sectional study in China. Gen Psychiatr. 2020;33(3):e100259. Published 2020 Jun 14. doi:10.1136/gpsych-2020-100259

Ratha, D. K., De, S., Kim, E. J., Plaza, S., Seshan, G. K., \& Yameogo, N. D. (2020). COVID-19 crisis through a migration lens (No. 147828, pp. 1-50). The World Bank.

Rao, M. A., \& Donaldson, S. I. (2015). Expanding opportunities for diversity in positive psychology: An examination of gender, race, and ethnicity. Canadian Psychology/Psychologie Canadienne, 56(3), 271.

Savage, A., McConnell, D., Emerson, E., \& Llewellyn, G. (2014). Disability-based inequity in youth subjective well-being: Current findings and future directions. Disability \& Society, 29(6), 877-892. https://doi-org.ccl.idm.oclc.org/10.1080/09687599.2014.880331

Schneider, S. M. (2016). Income inequality and subjective wellbeing: Trends, challenges, and research directions. Journal of Happiness Studies, 17(4), 1719-1739. https://doiorg.ccl.idm.oclc.org/10.1007/s10902-015-9655-3

Slopen, N., Lewis, T. T., \& Williams, D. R. (2016). Discrimination and sleep: A systematic review. Sleep Medicine, 18, 88-95. https://doi-org.ccl.idm.oclc.org/10.1016/j.sleep.2015.01.012

Thornton, J. (2020). Covid-19: A\&E visits in England fall by 25\% in week after lockdown. BMJ 369 doi: https://doi.org/10.1136/bmj.m1401

Usher, K., Bhullar, N., Durkin, J., Gyamfi, N., \& Jackson, D. (2020). Family violence and COVID-19: Increased vulnerability and reduced options for support. International Journal of Mental Health Nursing, 29, 549-552. doi:10.1111/inm.12735

van Dorn, A., Cooney, R. E., \& Sabin, M. L. (2020). COVID-19 exacerbating inequalities in the US. Lancet (London, England), 395(10232), 1243.

Van, D., McLaws, M. L., Crimmins, J., MacIntyre, C. R., \& Seale, H. (2010). University life and pandemic influenza: Attitudes and intended behaviour of staff and students towards pandemic (H1N1) 2009. BMC Public Health, 10(1), 130.

Van Lancker, W., \& Parolin, Z. (2020). COVID-19, school closures, and child poverty: A social crisis in the making. The Lancet Public Health, 5(5), e243-e244.

WHO (2020). WHO Director-General's opening remarks at the media briefing on COVID-19 - 11 March 2020. Retrieved from https://www.who.int/dg/speeches/detail/who-director-general-s-opening-remarksat-the-media-briefing-on-covid-19---11-march-2020

Yu, S., Levesque-Bristol, C., \& Maeda, Y. (2018). General need for autonomy and subjective well-being: A meta-analysis of studies in the US and East Asia. Journal of Happiness Studies, 19(6), 1863-1882. https://doi-org.ccl.idm.oclc.org/10.1007/s10902-017-9898-2

Zhang, H., Nurius, P., Sefidgar, Y., Morris, M., Balasubramanian, S., Brown, J., ... \& Mankoff, J. (2020). How Does COVID-19 impact Students with Disabilities/Health Concerns? arXiv preprint arXiv:2005.05438. 
Zhou, S. J., Zhang, L. G., Wang, L. L., Guo, Z. C., Wang, J. Q., Chen, J. C., ... \& Chen, J. X. (2020). Prevalence and socio-demographic correlates of psychological health problems in Chinese adolescents during the outbreak of COVID-19. European Child \& Adolescent Psychiatry, 1-10. 